\title{
Student Perceptions and Preferences for Feedback
}

\author{
Anna D. Rowe (Corresponding author) \\ Division of Economic and Financial Studies, Macquarie University \\ Sydney NSW 2109, Australia \\ Tel: 61-2-9850-8554Ｅmail: anna.rowe@mq.edu.au \\ Leigh N. Wood \\ Division of Economic and Financial Studies, Macquarie University \\ Sydney NSW 2109, Australia \\ Tel: 61-2-9850-4756 E-mail: leigh.wood@mq.edu.au
}

The research is financed by a Learning Excellence and Development (LEAD) grant from the Division of Economics and Financial Studies, Macquarie University, Australia.

\begin{abstract}
Provision of effective and high quality feedback has been identified as a key element of quality teaching. Despite its importance this area has been neglected in research to date; in particular research on student experiences of feedback. In a previous study Rowe and Wood (2008) invited economic and finance students (both undergraduate and postgraduate) to attend focus groups and individual interviews. In line with previous research the authors found that students valued feedback, and were aware of its importance to achieving learning outcomes. The aim of the present study is to extend the findings of the previous qualitative study with quantitative data. A survey was developed from themes identified in the focus groups and was distributed to a large cohort of students at Macquarie University and Canberra University. Some preliminary results are provided.
\end{abstract}

Keywords: Assessment, Feedback, Higher education, Student perceptions, Student preferences

\section{Introduction}

The provision of effective and high quality feedback has been identified as a key element of quality teaching and this view is well supported by meta-analytic studies (Astin, 1991; Black \& William, 1998; Hattie, 1987; Hounsell, 1987; Ramsden, 2003). Nevertheless this element of teaching has been largely neglected in research; in particular, the experience of students has not been extensively investigated. In a previous study by Rowe and Wood (2008) undergraduate and postgraduate economic and finance students from Macquarie University were invited to attend focus groups and individual interviews. The purpose of the study was to explore student perceptions of feedback. Participants consisted of 29 students with a wide range of backgrounds in terms of age, ethnic and language background and experience, so it was considered that the opinions expressed reflected the range of opinions of the student population. Due to problems of scheduling to fit into students' timetables, groups ranged in size from one to five depending on who was available in the timeslots. The interviewer asked a series of open-ended questions and probes were used if initial questions did not lead to developed responses. Focus groups were audio recorded and transcribed.

As shown in previous research (Higgins, Hartley \& Skelton, 2002; Hyland, 2000; Weaver, 2006), the authors found that students valued feedback and were aware of its importance to improved learning outcomes. Results indicated a diversity of preferences (that is, written/verbal, specific/general, group/individual), suggesting that a balanced approach in providing feedback would be most effective to meet individual needs. There were clear preferences for verbal feedback when generic and provided to the group as a whole. Written feedback was preferred, on the other hand, when offered as specific comments addressed to the individual on an assignment or exam. The overall message received from students was their need for teaching staff to provide more feedback. At the same time they expressed empathy for teachers, recognising the time and resource constraints of providing such a personalised service. The students interviewed in the previous study indicated that they wanted more engagement from their tutors, and while it is evident from the comments made that some tutors try to provide helpful feedback, this practice was found to be inconsistent. One possible explanation for this is time constraints due to large class sizes. The wide variety of responses received, when students were asked what they thought feedback was, suggests that many are confused about what to expect from tutors. While this could be attributed to differing perceptions about the role of feedback between students and teachers, another possibility is poor communication by teaching staff. It is suggested that the introduction of "assessment dialogues", as 
proposed by Carless (2006), may be beneficial here.

Feedback was considered particularly unhelpful when vague or untimely, or when not enough information was provided to make it useful. Many students wanted more face-to-face individual contact, but were aware that this can make unreasonable demands on lecturers' time. An interesting finding was that some students described feedback in emotional terms, for example by pointing to its role as a motivator and in providing reassurance, thus reducing their anxiety about a subject. Many commented that it was disrespectful of teaching staff to provide late feedback. Students expressed the value they placed on it and how they wanted their needs to be considered, for instance by saying that they wanted tutors to consider their feelings and point of view, and show care for their work. These findings were important enough for us to include a section on emotions in the survey developed for the current paper, to further explore this area.

\subsection{What is the role of feedback?}

Previous research has identified several constructs involved in the feedback process: the sources of feedback (teachers and students); the mode of feedback (how it is presented); the content (information conveyed); and the occasion (when it is presented) (Rucker \& Thomson, 2003). While there has been an attempt by some researchers to explain relationships between some variables, little has been done to integrate these constructs into a coherent theoretical model. Few studies have focused on teacher feedback about student performances, and fewer on student perceptions or preferences. Drew (2001) found that for students, feedback relating to all aspects of progress was important, not just performance in essays or exams (see also Deeprose \& Armitage, 2004).

Available research suggests that feedback is most effective when provided soon after task performance; is presented in a manner sensitive to the students' learning styles; clearly identifies strengths and weaknesses; has suggestions for improvements; and is constructive and motivating (Hattie \& Timperley, 2007; Parikh, McReelis \& Hodges, 2001; Rucker \& Thompson, 2003). Earlier research also established feedback as a necessary condition for student goal setting (Erez, 1977). Although the purpose of the present study was to explore student perceptions, a comparison of students' conceptualisations and research definitions is useful for refining teaching methods. For the purpose of this paper Hattie and Timperley's (2007) definition of feedback will be adopted, which they conceptualise as:

information provided by an agent (e.g. teacher, peer, book, parent, self, experience) regarding aspects of one's performance or understanding ... feedback is thus a "consequence of performance (Hattie \& Timperly, 2007, p.81).

In this study feedback is defined as information provided to students about their performance, and includes written comments on assignments, verbal responses provided in class or individually, postings on WebCT (the online student learning system), and peer- and self-evaluation forms of feedback.

\subsection{Why study student preferences?}

In recent years, increasing attention has been given to assessment and instruction. This is due largely to a growing trend for higher education institutions to adopt service orientation models in the provision of educational services (Hill, 2005; Higgins et al., 2002). As Birenbaum (2007) notes, such information not only assists higher education institutes to better serve their customers, but investigation of students' preferences for instruction and assessment is valuable for understanding a variety of other factors that drive the learning process and its outcomes. Some studies, for example, link student learning and testing preferences to performance differences (Phillips, 1999). Teacher evaluations have been found to be influenced by student preferences (Birenbaum, 2007). Unlike teaching preferences, which have received much attention, few studies regarding student assessment preferences are available, especially on feedback.

Some studies have looked at the interaction between preferences and student characteristics, that is, personality, attitudes, cognitive styles, learning orientations and strategies (Birenbaum, 2007). Positive feedback has been found to improve mood and satisfaction ratings in undergraduate students (Stake, 1982). Such studies suggest that preferences for feedback are related to students' self-esteem, self-concept and self-efficacy. The relationship between feedback and self-efficacy has been supported both by theory (Bandura, 1986; Zimmerman, 1995) and experimental studies (such as Lackey, 1997). Some gender differences in perceptions have been found (Rucker \& Thompson, 2003). In a study of medical students Parikh et al. (2001) found that individual feedback was the most strongly preferred type, with peer and group feedback also favoured. Assessment preferences have been linked to learning orientations and styles (Birenbaum, 1997; Entwistle \& Tait, 1990; Gijbels \& Dochy, 2006). For example, 'surface learners' have been found to prefer teaching and assessment procedures which allow them to memorise and reproduce factual contents of study materials, and 'deep learners' have been found to prefer courses which are intellectually challenging and where assessment procedures allow them to demonstrate their understanding (Biggs, 2003; Entwistle \& Tait, 1990; Gijbels \& Dochy, 2006). Birenbaum (2007) found that students preferred instruction and assessment that was on the teacher-dependency side of the dimension of learning.

Other studies point to differences in student and teacher perceptions. Deeprose and Armitage (2004) found that tutors failed to recognise the positive impact that their assessment feedback was having upon students. Reid and Johnston 
(2001) found that perceptions of what constitutes good teaching differ between students and academics. Such studies demonstrate the importance of considering the viewpoints of both students and academics, in that staff need to be more sensitive to student perceptions and students would benefit from a greater awareness of why particular teaching techniques are preferred by their teachers (Reid \& Johnson, 2001). Finally, Birenbaum (2007) notes the importance of studying preferences lies in the fact that, "students are aware of the factors that debilitate/facilitate their learning and this awareness influences their instruction and assessment preferences" (p.753).

\subsection{Research questions}

The current paper aims to extend the findings of Rowe and Wood's (2008) previous qualitative study with quantitative data. The focus of the present study is to investigate student perceptions and preferences for feedback. Preliminary explorations will also be made into the importance of emotions in the process. Building on themes that emerged from the focus groups, demographic variables such as gender, year of enrolment, enrolment type and first language were anticipated to affect student perceptions and preferences. For example, in the focus groups many international students said they preferred verbal feedback as this allowed them to clarify information. A final objective of the study is to explore the link between perceptions and preferences, that is, do students who value feedback perceive it differently, and how does this affect their preferences? It was anticipated that their preferences would fall into six identified categories (verbal/written, group/individual and specific/general feedback) and perceptions into two categories (practical/emotional).

\section{Method}

\subsection{Participants}

The participants were 883 undergraduate and 83 postgraduate students enrolled in a range of disciplines, the majority of which included commerce $(23.7 \%)$, accounting $(19.4 \%)$, actuarial studies $(17.2 \%)$ and business $(15.1 \%)$. There were 837 students from Macquarie University and 153 from the University of Canberra. Additional demographic data is presented in Table 1.

Table 1. Demographic variables

\begin{tabular}{|l|l|}
\hline Demographic variable & Number (\%) \\
\hline Gender & $500(51.5 \%)$ \\
Males & $468(48.2 \%)$ \\
\hline Females & $341(35.2 \%)$ \\
First year & $329(33.9 \%)$ \\
Second year & $142(14.6 \%)$ \\
Third year & $71 \quad(7.3 \%)$ \\
Fourth year or higher & $463(47.9 \%)$ \\
\hline Student Type & $503(52.1 \%)$ \\
International & \\
Domestic & $352(36.3 \%)$ \\
\hline First Language & $614(63.3 \%)$ \\
English & $S D=4.62), \mathrm{win})$ \\
Other &
\end{tabular}

The age of respondents ranged between 17 to 60 years $(M=21.66$ years, $S D=4.62)$, with $48.6 \%$ aged between $21-30$ years. For international students the average number of years lived in Australia was 9.61 years $(S D=9.35)$. The majority of international students were from China (45\%), Hong Kong (14.8\%), Korea (4.0\%), Malaysia (5.6\%) and Vietnam $(3.1 \%)$. This sample was representative of demographics within the faculty.

\subsection{Survey instrument}

Qualitative data from focus groups in the previous study were entered into NVIVO software. A questionnaire was developed using themes extracted from the data (refer to Appendix A) as well as themes identified in the literature. The questionnaire was divided into six sections: i) Demographic Data, ii) Type of Feedback, iii) Perceptions of Feedback, iv) Value of Feedback, v) Preferences for Feedback and vi) Suggestions for Feedback. Sections ii), iii) iv) and v) required students to indicate their level of agreement with a series of statements on a five-point Likert scale, ranging from "strongly disagree" to "strongly agree". For part of section ii) a five-point Likert scale with numerical points of 
reference $(0 \%, 25 \%, 50 \%, 75 \%$ and $100 \%)$ was used. This section was adopted from Parikh et al.'s (2001) feedback survey of American medical students. There were two open-ended questions on the importance of feedback (section iii) and suggestions to improve it (section vi). Once completed the questionnaire was administered to five colleagues and research assistants for validation purposes. Appropriate ethical approval was then sought and obtained.

\subsection{Design}

Using a randomised block design, the survey was administered by the researchers to students in classes at Macquarie University and at Canberra University from weeks two until weeks nine of Semester 2, 2007. Surveys were distributed, completed and collected during class time. At Macquarie, undergraduate and postgraduate students were surveyed from actuarial, accounting, business, economics and statistics classes. Copies of the survey were also left in the student centre. Undergraduate business/commerce and information technology students were recruited from Canberra University.

\section{Results}

A principle components analysis (PCA) was carried out on the core group of questions (Type of Feedback, Frequency of Feedback, Perceptions of Feedback and Value of Feedback) to determine whether they could be grouped by common dimensions. The results indicated that all groups of questions could be defined by one dimension with the exception of Preferences for Feedback which needed two.

Two new sub-groups were formed for this set (Pref A and Pref B). There appeared to be similarities between these two groups and two learning approaches (surface and deep) as conceptualised by Biggs (2003) and others. Pref A group preferred feedback that allowed them to think deeply about their subject matter and encouraged independent learning through reflection. Statements indicative of such responses include, "I like it when tutors guide us to work out the answers ourselves", "general feedback in class helps me to learn independently", and, "it is more important for me to see the reason why I received a particular grade, than to know how other students went." By contrast the Pref B group were less interested in understanding the material but wanted feedback which gave them the answers or information about the tutors' marking criteria. Responses indicative of this group included such statements as, "I prefer it when tutors just give us the answers", "the grade is more important to my learning than feedback", and, "I don't like it when teaching staff encourage questions in lectures because it waste time." Emotion items included in section ii) failed to appear as a separate dimension.

An independent-samples t-test was conducted to compare scores for Type of Feedback, Frequency of Feedback, Perceptions of Feedback, Value of Feedback and Preferences for Feedback (across both groups, Pref A and Pref B) for Macquarie and Canberra University students. No significant differences were found between these groups for any of the feedback measures.

Independent t-tests were then used to determine whether there were any differences between demographic groups across the subscales. Men and women were found to differ significantly across all measures, as can be seen in Table 2 . Women's mean scores for all feedback measures were higher than those of men.

Table 2. Effect of gender on feedback subscales

\begin{tabular}{|l|l|l|l|l|}
\hline Feedback Scale & $t$ & $d f$ & Sig. (2-tailed) & $\begin{array}{l}\text { Mean Difference } \\
\text { (on a five point } \\
\text { Likert Scale) }\end{array}$ \\
\hline Type of Feedback & 2.75 & 963 & $p<.05$ & .09 \\
\hline $\begin{array}{l}\text { Perceptions } \\
\text { of Feedback }\end{array}$ & 5.12 & 951.12 & $p<.001$ & .14 \\
\hline Value of Feedback & 4.09 & 951 & $p<.001$ & .13 \\
\hline $\begin{array}{l}\text { Preference } \\
\text { Group A }\end{array}$ & 3.89 & 920.24 & $p<.001$ & .11 \\
\hline $\begin{array}{l}\text { Preference } \\
\text { Group B }\end{array}$ & 2.55 & 951 & $p<.05$ & .08 \\
\hline
\end{tabular}

Further t-tests on each of the perception questions revealed mean differences ranging from .007 to .290 . The most significant difference between men $(M=3.65, S D=.86)$ and women $(M=3.9, S D=.76)$ was in their response to the statement, "when the tutor gives me feedback it shows me that they care about the work I have done." Women also agreed more than men with statements such as: "feedback tells me what I need to do to improve my performance in a subject", "feedback explains my grade for a subject", "feedback tells me what the expectations of the lecturer/tutor are", "feedback motivates me to study", and, "lecturers who provide feedback care about what students think." These differences were small, however. T-tests on gender and preferences revealed mean differences ranging between .01 
and .21 , which were considered too inconsequential to report.

Significant differences were found between international $(M=3.01, S D=.509)$ and domestic students $(M=3.16, S D=.494)$ on Type of Feedback, $t(963)=5.34, p<.01$ (mean difference .17), suggesting that domestic students are more satisfied with the amount and type of feedback that they are receiving. A significant difference was also found between international $(M=3.01, S D=.51)$ and domestic students $(M=3.12, S D=.49)$ for Pref B group, $t(951)=-4.55, p<.001$. This difference was small (-.15), and no further analyses were carried out. A one-way between-groups analysis of variance was conducted to explore the impact of year of enrolment (undergraduate students only) on the above measures. No significant differences were found with the exception of Type of Feedback, $F(3,878)=2.84, p<.05$. First year students $(M=3.44, S D=.49)$ were found to be more satisfied with the Type of Feedback they were receiving than fourth year students $(M=3.26, S D=.57)$. The mean differences, however, are small and such results may be caused by the large sample size. This finding is contrary to comments made by first and second year students in the focus groups, who were generally more dissatisfied with the amount and quality of feedback they were receiving (due to large class sizes) than those of third and fourth year students. No significant differences were found between undergraduate and postgraduate students across any of the measures.

Preference group data were analysed by multiple regression, using demographic variables (university, age, gender, enrolment type and language) as regressors. The regression was a poor fit for both Pref $A\left(R^{2}\right.$ adj $\left.=1 \%\right)$ and Pref $B\left(R^{2}\right.$ adj $=3.7 \%$ ), however, possibly due to the large sample size significant relationships were evident. The effect of gender was significant for both Pref A, $F(1,852)=14.54, p<.001 ; M($ males=3.71, females=3.82), and Pref $\mathrm{B}, F(1,852)=8.90, p<.05$; $M($ males $=3.05$, females=3.15). Enrolment type, $F(1,852)=1.51, p<.05 ; M($ international students $=3.05$, domestic students=3.4), and First language, $F(1,852)=6.23, p<.05 ; M($ English=3.15, language other than English=3.04), were also found to be significant predictors of student preferences (Pref B group only). No other significant relationships were found.

\section{Discussion}

\subsection{Findings}

This paper provides preliminary results that extend an earlier qualitative study. A more comprehensive analysis of the data is currently being undertaken and will be published at a later date. While it was expected that preferences for feedback would fall into the six categories identified (such as verbal/written, group/individual and specific/general feedback), factor analysis identified two dimensions of preference. The most interesting finding of the study appears to be a link between student feedback preferences and learning approaches. Previous studies have identified a relationship between learning strategies and assessment preferences (Birenbaum, 1997; Entwistle \& Tait, 1990; Gijbels \& Dochy, 2006). The characteristics of the two preference dimensions identified appear to reflect two learning approaches (surface and deep) as conceptualised by Biggs (2003) and others (Entwistle \& Tait, 1990; Gijbels and Dochy, 2006). Pref A students appear to reflect deep learners whose preferred approach is to engage meaningfully in learning that enhances their understanding of the material. These students prefer feedback that allows them to understand the material and welcome the opportunity to engage with the lecturer. Perhaps this reflects a more self-regulated approach to learning (Birenbaum, 2007). Pref B students appear to fit the category of surface learners whose preferred approach is to meet course requirements with minimum effort. They prefer positive feedback that gives them the answers and dislike class participation. Perhaps these students could be viewed as falling into the teacher-dependent category (Birenbaum, 2007).

Very few significant differences were found between any of the demographic variables. Neither institution nor year of study significantly affected how students valued or perceived feedback, or their preferences. Some minor differences were found between international and domestic students on their perceptions of the feedback being provided to them and their preferences, however, these were not highly significant. Similarly, year of enrolment was found to significantly effect student perceptions of the type of feedback they were receiving, with third and fourth year students reporting lower levels of satisfaction than first and second years. Gender emerged as the demographic variable most likely to affect perceptions and preferences, with men and women differing significantly across all measures pertaining to this: women were more satisfied with the amount and type of feedback they were receiving, valued feedback more and seemed to view feedback as important for emotional reasons more than men. While these differences were small they are noteworthy. It is difficult to compare the present gender findings to previous studies (such as Rucker \& Thomson, 2003) because of the measurement of different constructs.

The results of the regression analyses suggest that demographic variables are a poor predictor of student feedback preferences. The small amount of variance in preferences explained by demographics suggests that there are other variables which need to be explored (such as the extent to which students value feedback, and their perceptions of it). It is recommended that further analyses of the data look closely at the relationships between such variables and student preferences. It is anticipated that students who value learning are more likely to hold a deep learning approach, while surface learners will hold a cynical view of education (Biggs, 2003). Based on the overall findings, it is suggested that 
the provision of good practice for everyone is more important than accounting for individual differences, and that clearly-communicated feedback should work successfully across all demographic groups. As per the focus groups, many students reported that they were not receiving enough feedback. The importance of teachers providing effective and timely feedback is highlighted by the following comment made by an undergraduate international student: "'the sound of silence' is not a happy song."

\subsection{Challenges}

There were challenges to the present study. Some students did not fill in the last page, which implies that the survey may have been too lengthy. Other potential factors that may have introduced a bias were an imbalance in sampling; for example, mainly day classes were surveyed. A further observation is that instructions given to classes were not controlled. These factors may have affected the final results. Despite these limitations the current study provides an innovative step towards an understanding of the dimensions of student perceptions and preferences for feedback.

\subsection{Future directions}

Further analyses are currently being undertaken using this data to explore other possible relationships between variables yet to be determined. Future research is needed on the role of emotions in learning - specifically emotions and feedback. Although statements on emotions in section ii) (Type of Feedback) failed to emerge as a separate dimension in the factor analysis, this could be due to the small number of items allocated to this theme. Many written comments obtained from the survey point to emotional factors, including several requests for the provision of feedback to be made more personal. For example:

It [feedback] motivates and encourages students in the right direction. It should be personal and able to be applied easily. Not only is it justification, but it's advice. (Undergraduate domestic student -female)

It [feedback] shows the tutor/lecturer is in tune and cares about his/her students. (Undergraduate international student - female)

\section{Interaction between tutor and students must be encouraged. (Undergraduate domestic student - female)}

These were interesting comments made by female students. Given that women's responses were significantly different from men's on two statements linking the provision of feedback to the extent to which lecturers care, this suggests that for women receiving feedback holds as much emotional as academic significance. Written comments were also found to complement qualitative data from the focus groups, with similar themes emerging - for example, the role of feedback as a motivator, in reducing anxiety, providing encouragement and making students feel cared for (Rowe \& Wood, 2008). Students' written comments from the survey have not been reported extensively in this paper, but they will be the focus of a later publication.

\subsection{Conclusions}

The present study illustrates students' perceptions about the role of feedback, and adds to the emerging literature focussed on improving student learning and the student experience. The survey presented students with an opportunity to reflect on the significance of feedback in their learning. The findings highlight the importance of developing a much deeper dialogue with students about issues related to the individual meaning of receiving feedback. A student-participative approach to teaching and learning is essential for two reasons: firstly, the way that students perceive the learning context and the way they approach learning affects their learning outcomes and, secondly, student-teacher concepts of what constitutes good teaching often differ (Gijbels \& Dochy, 2006; Reid \& Johnson, 1999). An important finding of the study was a possible link between student feedback preferences and learning approaches. Approaches to learning have been extensively studied so now that literature can be applied to student preferences. The preliminary findings in this study imply that the provision of appropriate and timely feedback promotes deep learning in students.

Universities are increasingly recognising that feedback is an important way of improving their teaching ratings. Indirectly this then assists them to secure critical learning and teaching performance funding. Future directions for research are to further explore the relationship between student preferences and approaches to learning (such as deep and surface), and to consider the impact of other demographic variables such as age and country of origin. The effect of feedback on student emotions is another promising area of investigation.

\section{References}

Astin, A.W. (1991). Assessment for excellence: The philosophy and practice of assessment and evaluation in higher education. New York: Macmillan Publishing Company.

Bandura, A. (1986). Social foundations of thought and action: A social cognitive theory. Englewood Cliffs, New Jersey: Prentice-Hall.

Black, P., \& William, D. (1998). Assessment and classroom learning. Assessment in Education: Principles, Policy \& Practice, 5 (1), 7-74. 
Biggs, J. (2003). Teaching for quality learning at university: What the student does. Buckingham: Society for Research into Education \& Open University Press.

Birenbaum, M. (1997). Assessment preferences and their relationship to learning strategies and orientations. Higher Education, 33 (1), 71-84.

Birenbaum, M. (2007). Assessment and instruction preferences and their relationship with test anxiety and learning strategies. Higher Education, 53, 749-768.

Carless, D. (2006). Differing perceptions in the feedback process. Studies in Higher Education, 31 (2), 219-233.

Deeprose, C., \& Armitage, C. (2004). Reports: Giving formative feedback in higher education. Psychology Learning and Teaching, 4 (1), 43-46.

Drew, S. (2001). Student perceptions of what helps them to learn and develop in higher education. Teaching in Higher Education, 6 (3), 309-332.

Entwistle, N., \& Tait, H. (1990). Approaches to learning, evaluations of teaching, and preferences for contrasting academic environments. Higher Education, 19 (2), 169-194.

Erez, M. (1977). Feedback: A necessary condition for the goal setting-performance relationship. Journal of Applied Psychology, 62 (5), 624-627.

Gijbels, D., \& Dochy, F. (2006). Students' assessment preferences and approaches to learning: Can formative assessment make a difference? Educational Studies, 32 (4), 399-409.

Hattie, J.A. (1987). Identifying the salient facets of a model of student learning: A synthesis of meta-analyses. International Journal of Educational Research, 11, 187-138.

Hattie, J.A., \& Timperley, H. (2007). The power of feedback. Review of Educational Research, 77, 81-112.

Higgins, R., Hartley, P., \& Skelton, A. (2002). The conscientious consumer: Reconsidering the role of assessment feedback in student learning. Studies in Higher Education, 27 (1), 53-64.

Hill, F.M. (1995). Managing service quality in higher education: The role of the student as primary consumer. Quality Assurance in Education, 3, 10-21.

Hounsell, D. (1987). Essay writing and the quality of feedback. In J.T.E. Richardson, M.W. Eysenck \& D. Warren-Piper (Eds.), Student learning: Research in education and cognitive psychology. Milton Keynes: Society for Research into Higher Education, Open University Press.

Hyland, P. (2000). Learning from feedback in assessment. In P. Hyland \& A. Booth (Eds.), The practice of university history teaching (pp. 233-247). Manchester: Manchester University Press.

Lackey, J.R. (1997). The effects of feedback on motivation and changes in written performance. Paper presented at the Annual Meeting of the American Education Research Association. Chicago, IL.

Parikh, A., McReelis, K., \& Hodges, B. (2001). Student feedback in problem based learning: A survey of 103 final year students across five Ontario medical schools. Medical Education, 35, 632-636.

Phillips, F. (1999). Business students' learning preferences and associated task performance. Journal of Education for Business, September/October, 27-32.

Ramsden, P. (2003). Learning to teach in higher education (2nd Ed.). London: Routledge.

Reid, D.J., \& Johnston, M. (1999). Improving teaching in higher education: Student and teacher perspectives. Educational Studies, 25 (3), 269-281.

Rucker, M. L., \& Thomson, S. (2003). Assessing student learning outcomes: An investigation of the relationship among feedback measures. College Student Journal, 37 (3), 400-404.

Rowe, A.D., \& Wood, L.N. (2008). What feedback do students want? Australian Association for Research in Education (AARE) International Education Research Conference. Freemantle, Australia (CD \& online). Available: www.aare.edu.au/07pap/row07086.pdf (January 18, 2008)

Stake, J.E. (1982). Reactions to positive and negative feedback: Enhancement and consistency effects. Social Behavior and Personality, 10 (2), 151-156.

Weaver, M.R. (2006). Do students value feedback? Student perceptions of tutors' written responses. Assessment \& Evaluation in Higher Education, 31 (3), 379-394.

Zimmerman, B.J. (1995). Self-efficacy and educational development. In A. Bandura (Ed.), Self-efficacy in changing societies (pp. 202-231). Cambridge: Cambridge University Press. 


\section{Appendix A - Student Feedback Questionnaire}

Macquarie University is interested in student learning experiences and wishes to investigate student perceptions of and preferences for feedback, with the aim of improving learning and teaching. There are no right or wrong answers in this questionnaire. Please complete the following questions on the basis of your experience studying at the University. Any information or personal details gathered in the course of this study will be kept confidential. No individual will be identified in any publication of the results. Only the researchers will have access to the data.

\section{Demographic Data}

a) What program are you enrolled in?

b) What gender are you? O Female O Male

c) What is your age? ___ years

d) Are you an undergraduate or postgraduate student?

$O$ undergraduate $O$ postgraduate

e) If undergraduate, are you a first, second, third or fourth year student?
O (1)
$\mathrm{O}(2)$
O (3)
$\mathrm{O}(4)$

f) Are you an international student? OYes ONo

If yes, which country do you come from?

g) Is English your first language? OYes ONo

If no, what is your first language?

h) How many years have you lived in Australia? years

\section{Feedback Provided by the University}

Please indicate your level of agreement with the following statements:

\begin{tabular}{|c|c|c|c|c|c|}
\hline & $\begin{array}{l}\text { Strongly } \\
\text { Disagree }\end{array}$ & Disagree & Neutral & Agree & $\begin{array}{l}\text { Strongly } \\
\text { Agree }\end{array}$ \\
\hline $\begin{array}{l}\text { I receive enough feedback from my lecturers and } \\
\text { tutors }\end{array}$ & O & O & O & O & $\mathrm{O}$ \\
\hline $\begin{array}{l}\text { The feedback I receive is relevant to my goals as a } \\
\text { student }\end{array}$ & $\mathrm{O}$ & 0 & $\mathrm{O}$ & O & $\mathrm{O}$ \\
\hline $\begin{array}{l}\text { The feedback I receive is related to the purpose of } \\
\text { the assignment }\end{array}$ & 0 & O & 0 & 0 & 0 \\
\hline $\begin{array}{l}\text { My lecturers and tutors provide enough information } \\
\text { to make feedback useful }\end{array}$ & $\mathrm{O}$ & $\mathrm{O}$ & $\mathrm{O}$ & 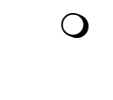 & $\mathrm{O}$ \\
\hline $\begin{array}{l}\text { Feedback on assignments is always provided within } \\
\text { two weeks }\end{array}$ & $\mathrm{O}$ & $\mathrm{O}$ & O & $\mathrm{O}$ & $\mathrm{O}$ \\
\hline $\begin{array}{l}\text { Teaching staff are always willing to provide } \\
\text { feedback }\end{array}$ & O & $\mathrm{O}$ & $\mathrm{O}$ & 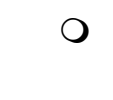 & O \\
\hline $\begin{array}{l}\text { The feedback I receive can be applied to my studies } \\
\text { and/or work }\end{array}$ & $\mathrm{O}$ & $\mathrm{O}$ & $\mathrm{O}$ & 0 & O \\
\hline $\begin{array}{l}\text { Class feedback is presented in a way so that } \\
\text { everyone can participate }\end{array}$ & $\mathrm{O}$ & $\mathrm{O}$ & $\mathrm{O}$ & 0 & O \\
\hline $\begin{array}{l}\text { Teaching staff need to be more active in providing } \\
\text { feedback }\end{array}$ & 0 & 0 & $O$ & O & 0 \\
\hline
\end{tabular}


Please indicate how often (as a percentage of time) you receive the following types of feedback:

No feedback

$\begin{array}{ccccc}0 \% & 25 \% & 50 \% & 75 \% & 100 \% \\ 0 & 0 & 0 & 0 & 0 \\ 0 & 0 & 0 & 0 & 0 \\ 0 & 0 & 0 & 0 & 0 \\ 0 & 0 & 0 & 0 & 0 \\ 0 & 0 & 0 & 0 & 0 \\ 0 & 0 & 0 & 0 & 0 \\ 0 & 0 & 0 & 0 & 0 \\ 0 & 0 & 0 & 0 & 0\end{array}$

\section{Perceptions of Feedback}

Please indicate your level of agreement with the following statements. When responding think about what you consider to be the most important aspects of feedback:

\begin{tabular}{|c|c|c|c|c|}
\hline $\begin{array}{l}\text { Strongly } \\
\text { Disagree }\end{array}$ & Disagree & Neutral & Agree & $\begin{array}{l}\text { Strongly } \\
\text { Agree }\end{array}$ \\
\hline 0 & O & 0 & $\mathrm{O}$ & O \\
\hline $\mathrm{O}$ & $\mathrm{O}$ & $\mathrm{O}$ & $\mathrm{O}$ & $\mathrm{O}$ \\
\hline 0 & O & 0 & O & $\mathrm{O}$ \\
\hline $\mathrm{O}$ & 0 & $\mathrm{O}$ & $\mathrm{O}$ & 0 \\
\hline $\mathrm{O}$ & $\mathrm{O}$ & $\mathrm{O}$ & $\mathrm{O}$ & $\mathrm{O}$ \\
\hline $\mathrm{O}$ & O & $\mathrm{O}$ & O & $\mathrm{O}$ \\
\hline O & 0 & $\mathrm{O}$ & $\mathrm{O}$ & 0 \\
\hline $\mathrm{O}$ & O & 0 & O & $\mathrm{O}$ \\
\hline $\mathrm{O}$ & O & $\mathrm{O}$ & $\mathrm{O}$ & O \\
\hline O & $\mathrm{O}$ & $\mathrm{O}$ & $\mathrm{O}$ & $\mathrm{O}$ \\
\hline 0 & 0 & 0 & 0 & 0 \\
\hline $\mathrm{O}$ & O & O & $\mathrm{O}$ & $\mathrm{O}$ \\
\hline $\mathrm{O}$ & O & O & O & $\mathrm{O}$ \\
\hline 0 & 0 & 0 & 0 & 0 \\
\hline O & O & O & $\mathrm{O}$ & $\mathrm{O}$ \\
\hline
\end{tabular}

Feedback is a justification of the grade I have received

When the tutor gives me feedback it shows me that they care about the work I have done

Feedback tells me what I need to do to improve my performance in a subject

Feedback explains my grade for an assignment I deserve feedback when I put so much effort into tutorials and assignments

When the tutor provides feedback I don't worry as much about the subject

Feedback is a response from the tutor to something I have said in class

When I receive a lot of feedback I feel encouraged

Feedback is any individual contact with the lecturer

Receiving feedback does not reduce my anxiety about a subject

Feedback is an evaluation of my strengths and weaknesses

Lecturers who provide feedback care about what students think

Feedback tells me what the expectations of the lecturer/tutor are

Feedback motivates me to study

When I don't receive any feedback I feel that the lecturer does not respect me 
Feedback is important because ...

\section{Value of Feedback}

Please indicate your level of agreement with the following statements:

$\begin{array}{ccccc}\begin{array}{c}\text { Strongly } \\ \text { Disagree }\end{array} & \text { Disagree } & \text { Neutral } & \text { Agree } & \begin{array}{c}\text { Strongly } \\ \text { Agree }\end{array} \\ 0 & 0 & 0 & 0 & 0 \\ 0 & 0 & 0 & 0 & 0 \\ 0 & 0 & 0 & 0 & 0 \\ 0 & 0 & 0 & 0 & 0 \\ 0 & 0 & 0 & 0 & 0\end{array}$

\section{Preferences for Feedback}

Please indicate your level of agreement with the following statements:

Feedback is important to me

I always collect my assignments

I always read the feedback on my assignments

I use feedback to try and improve my results in future assignments

Feedback is only useful when I receive a low grade

$\begin{array}{ccccc}\begin{array}{c}\text { Strongly } \\ \text { Disagree }\end{array} & \text { Disagree } & \text { Neutral } & \text { Agree } & \begin{array}{c}\text { Strongly } \\ \text { Agree }\end{array} \\ 0 & 0 & 0 & 0 & 0 \\ 0 & 0 & 0 & 0 & 0 \\ 0 & 0 & 0 & 0 & 0 \\ 0 & 0 & 0 & 0 & 0 \\ 0 & 0 & 0 & 0 & 0 \\ 0 & 0 & 0 & 0 & 0 \\ 0 & 0 & 0 & 0 & 0 \\ 0 & 0 & 0 & 0 & 0 \\ 0 & 0 & 0 & 0 & 0 \\ 0 & 0 & 0 & 0 & 0 \\ 0 & 0 & 0 & 0 & 0 \\ 0 & 0 & 0 & 0 & 0 \\ 0 & 0 & 0 & 0 & 0 \\ & & & & \end{array}$


Participating in classroom discussion is the most effective way to learn

Marking grids are good because I don't feel like I am being personally singled out

Strongly
Disagree

$\bigcirc$

$\bigcirc$

$\bigcirc$

○

$\bigcirc$

O

$\bigcirc$

Disagree

Neutral

Agre

gree

Strongly

Agree

O

O

O

O

O

$\mathrm{O}$

$\bigcirc$

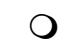

$\bigcirc$

O

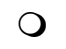

$\bigcirc$

$\bigcirc$

$\bigcirc$

$\bigcirc$

$\bigcirc$

○

$\bigcirc$

O

O

O

O

O

O

O

O

O

O

O

O

O

O

○

o

O

O
Written feedback is unreliable because tutors have different marking criteria

The grade is more important to my learning than feedback

I prefer general feedback in class because it's not personal

I prefer verbal feedback because I can communicate with the tutor and clarify information

It is more important for me to see the reason why I received a particular grade, than to know how other students went

Group feedback is best because I can see where other students have experienced similar problems

Marking grids are too vague

I like it when tutors guide us to work out the answers ourselves

I forget verbal feedback easily

I prefer it when tutors just give us the answers

Written feedback is better because I can refer to it later

\section{Suggestions for Feedback}

What are your suggestions for improving feedback at Macquarie? 